\title{
Gender disparities in advanced endoscopy fellowship: Women in Endoscopy (WIE) perspective
}

\section{다 (용}

\section{Authors}

Uzma D. Siddiqui ${ }^{1}$, Jeanin E. van Hooft ${ }^{2}$, Amrita Sethi ${ }^{3}$

\section{Institutions}

1 University of Chicago Center for Endoscopic Research and Therapeutics (CERT), Chicago, Illinois, United States

2 Leiden University Medical Center, Gastroenterology and Hepatology LUMC, Leiden, the Netherlands

3 Columbia University Medical Center, Gastroenterology and Hepatology, New York, New York, United States

\section{Bibliography}

Endosc Int Open 2021; 09: E505-E506

DOI 10.1055/a-1339-1432

ISSN 2364-3722

(C) 2021. The Author(s).

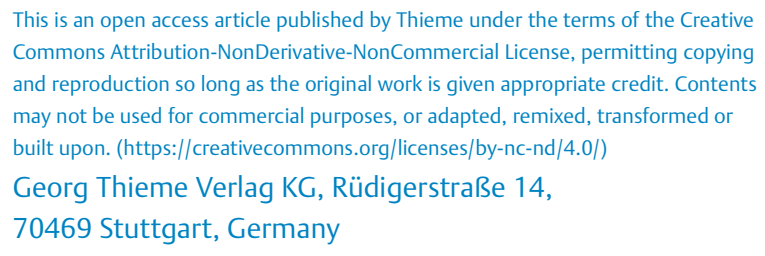

This is an open access article published by Thieme under the terms of the Creative Commons Attribution-NonDerivative-NonCommercial License, permitting copying and reproduction so long as the original work is given appropriate credit. Contents may not be used for commercial purposes, or adapted, remixed, transformed or built upon. (https://creativecommons.org/licenses/by-nc-nd/4.0/) Georg Thieme Verlag KG, Rüdigerstraße 14, 70469 Stuttgart, Germany

Corresponding author Amrita Sethi, Columbia University Medical Center Gastroenterology and Hepatology, 161 Fort Washington Ave Suite 852A, New York New York 10032, United States Fax: +1-212-3055576 as3614@cumc.columbia.edu
As female therapeutic endoscopists and governing board members of Women in Endoscopy (WIE), our group applauds Yu, et al for their study examining "Gender Disparities in Advanced Endoscopy Fellowship" [1]. While this study focuses on advanced endoscopy fellowship programs utilizing the ASGE Match process in the United States, these results highlight the global issue of unequal gender representation in this field. The authors attempt to determine the various reasons as to why only $12.8 \%$ of fellows that matched in advanced endoscopy fellowship (AEF) program in 2019.

The presence and identification of female role models and mentors play a significant role in attracting and retaining women in almost every professional field, including advanced endoscopy. This study revealed that women were significantly underrepresented in US advanced endoscopy programs with low rates $(<20 \%)$ of women in leadership roles (program director or chief), advanced endoscopy faculty, and as fellows. Not surprisingly, there was a correlation between programs having female advanced endoscopy faculty to those that matched female advanced endoscopy fellows. Furthermore, the study identified that the main barriers to recruitment of women into advanced endoscopy reported in this dataset included concerns about inflexible hours/call, exposure to fluoroscopy, and a lack of female endoscopists at courses and mentorship.

The findings of the study provide quantifiable data about issues that long have been recognized by women already in advanced endoscopy careers, and that have led to the creation of initiatives for advocacy, such as WIE. The organization's mission statement reflects our commitment to overcoming some of the barriers that have now been objectively identified, and is as follows, "WIE is the global organization that champions the advancement of women through education, professional growth and leadership development." This organization recognizes that lack of female visibility and mentorship are global issues that must be addressed to improve parity and to foster careers for women in the field. It is of utmost importance to provide role models for female trainees to address their concerns and provide insight into how to overcome the perceived barriers to success in this male-dominated field. WIE is joined by similar efforts in many other gastroenterology societies, including the American College of Gastroenterology, the American Gastroenterological Association, the American Society for Gastrointestinal Endoscopy, and the European Society of Gastrointestinal Endoscopy, with their respective women special interest groups and diversity committees.

WIE events and society discussions revolve around amplifying female voices and increasing diversity in the workforce by creating opportunities for women to be seen as leaders working with industry, serving as faculty for conferences, and conducting research. Focus is also given to nurturing leadership skills and encouraging goals that include promotion to leadership positions. In addition, efforts have been made to create an environment that normalizes having female faculty on course panels and performing live endoscopy procedures to serve as inspiration to the next generation of female trainees. While the goals of the society, and others like it, are to promote wom- 
en in the field, WIE fully acknowledges that this requires partnership with our male colleagues and their recruitment in these efforts.

As this recent study astutely illustrates, the numbers of women in advanced endoscopy training programs can only be increased by bringing attention to this matter and working in a collaborative manner. Now that gender disparities and some of the causes have been clearly documented with data, this is the time for those of us interested in the advancement of women, including in interventional endoscopy, to seize this opportunity for transformation and develop the process by which to create change.
Competing interests

Amrita Sethi: Consultant to Boston Scientific, Olympus, Medtronic, Fujifilm, Micro-tech; travel expenses paid by ERBE, Covidien, Cook, Endogastric Solutions and ER Squibb; Societies: President, Women in Endoscopy; ACG, ASGE, AGA; Editorial board GIE, TIGE Uzma Siddiqui: Consultant: Olympus, BSCl, Medtronic, ConMed; Speaker: BSCI, Piinnacle Biologics, Ovesco. Medtronic; Professional societies: ASGE, ACG, AGA, WIE (Vice-President) Jeanin van Hooft: Consultant: Olympus, BSCl, Medtronic, Cook; Speaker-BSCI, Medtronic, Prof societies: ASGE, WIE, ESGGE, UED

\section{Reference}

[1] Yu JX, Berzin TM, Enestvedt B et al. Gender disparities in advanced endoscopy fellowship. Endosc Int Open 2021; 09: E338-E342 